\title{
Fabrication of Radiographic Stent for Dental implants: A simplified approach
}

Bhochhibhoya $\mathrm{A}^{1 *}$, Vaidya $\mathrm{S}^{2}$

${ }^{1}$ Lecturer, Department of Prosthodontics and Maxillofacial Prosthetics

${ }^{2}$ Lecturer, Department of Periodontology and Oral Implantology

Nepal Medical College, Kathmandu, Nepal

\section{Introduction}

$\mathrm{T}$ he demand for implant treatments is on the rise and so are the expectations. In all stages of implant dentistry, careful treatment planning results in a more predictable outcome. ${ }^{1}$ The ultimate goal of implant placement is the success of final restoration. Patient judges the success based on implant position, function and esthetic excellence of the final dental restoration. The traditional methodology behind the implant workflow has involved first placing the implant in the available bone. At that point, the clinician then determines where the crown should be positioned. Prostheticdriven planning, however, reverses this process with a crown-down approach. With prosthetic driven planning, the outcome lies at the heart of the workflow, driving the process from start to finish.

Radiographic stent is the key for predictable implant placement. It is the best way to evaluate the relationship of available bone. It allows evaluation of available bone relative to "prosthetically driven" implant position. ${ }^{2}$ Radioopaque material embedded in an acrylic stent placed in proposed fixture locations which may be metal objects (bearing balls and wires), gutta-percha, lead foil, barium impregnated into resin, porcelain teeth and mixture of resin and amalgam. ${ }^{2,3}$

\section{*Corresponding Author}

Dr. Amar Bhochhibhoya, Lecturer

Department of Prosthodontics and Maxillofacial

Prosthetics, Nepal Medical College,

Kathmandu, Nepal

E-mail:amarbhochhibhoya@gmail.com
Radiographs help in determining amount of space and available bone. CBCT (cone beam computed tomography) scan gives more accurate and reliable assessment of bone (quality and quantity) and location of anatomic structures. The present article illustrates a straight forward technique for the fabrication of a radiographic template with heat cure acrylic resin for implant planning.

\section{Technique}

1. Pour the diagnostic cast in stone (Kalstone, India). Complete diagnostic wax up on the proposed replacement teeth (DPI, India). For enhanced stability in the mouth, make sure that the template extends at least 2 teeth on either side of the edentulous area. ${ }^{4}$ (Fig. 1, 2)

2. Process the wax pattern with heat polymerizing clear acrylic resin (Trevalon Densply, India). (Fig.3)

3. Drill hole with a round bur (H71 E; Komet USA) on the center of cingulum along the long-axis of the proposed tooth replacement. (Fig 4, 5)

4. Embed and condense radio opaque material in the drilled hole. Glue a 2-mm wide lead strip, cut from any intraoral dental film lead foil, outlining the circumference of the tooth over the implant site. (Fig 6,7)

5. Verify for accuracy of fit and adaption of the stent in relation to the remaining teeth and soft tissues. Make adjustments and polish if necessary. (Fig. 8)

6. Instruct the patient to wear the stent during the CBCT scan. (Fig. 9) 

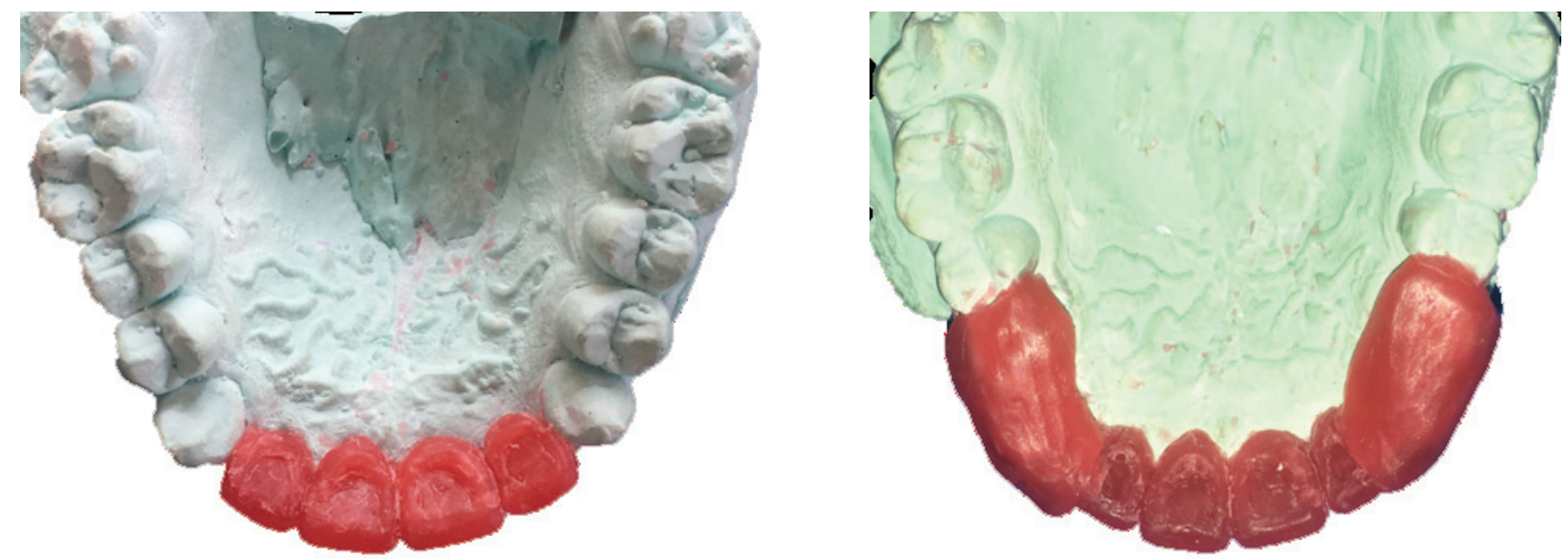

Figure 1, 2: Complete diagnostic wax up on the proposed replacement teeth.

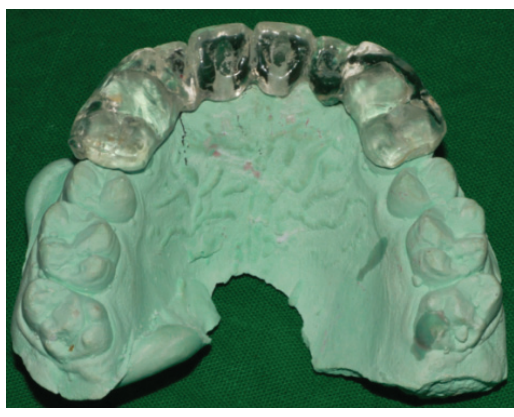

Figure 3: Wax pattern processed with heat polymerizing clear acrylic resin

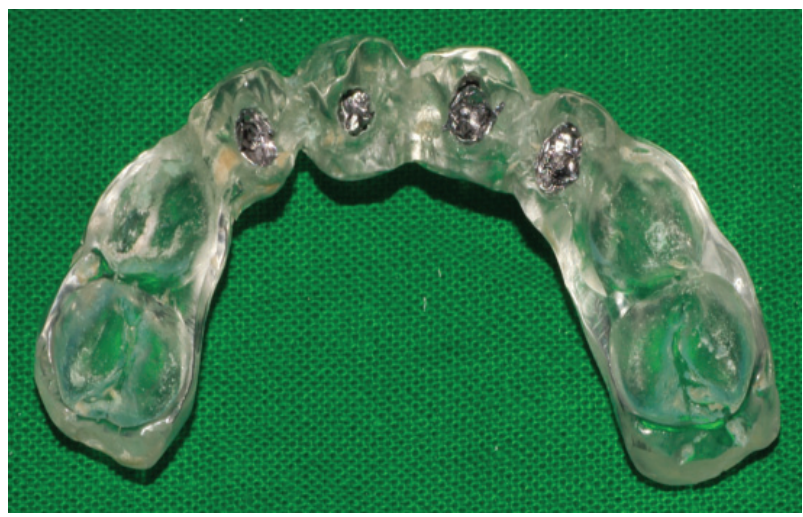

Figure 6: Radio opaque material embedded in the drilled holes

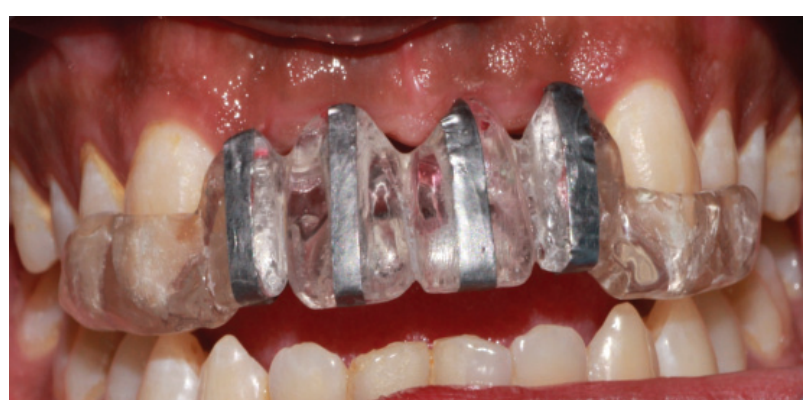

Figure 8: Try in of the radiographic stent before CBCT scan

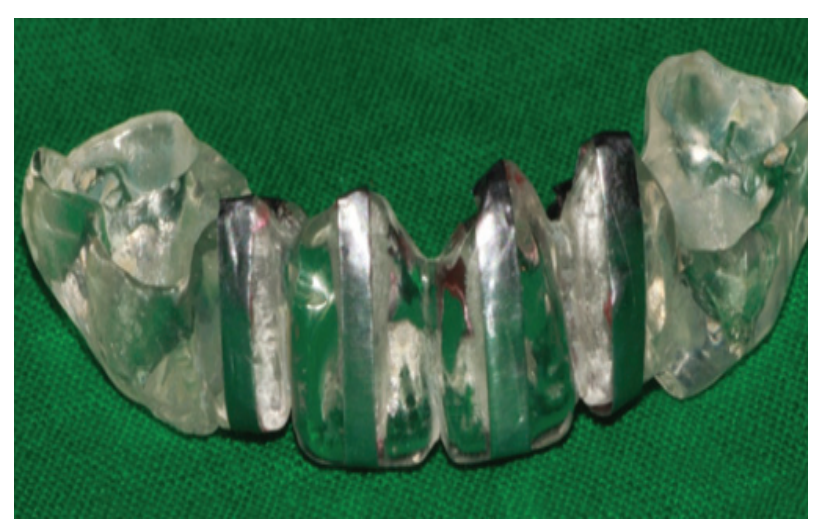

Figure 7: Circumference radiopaque indicator lead strip outlining the tooth over the implant site

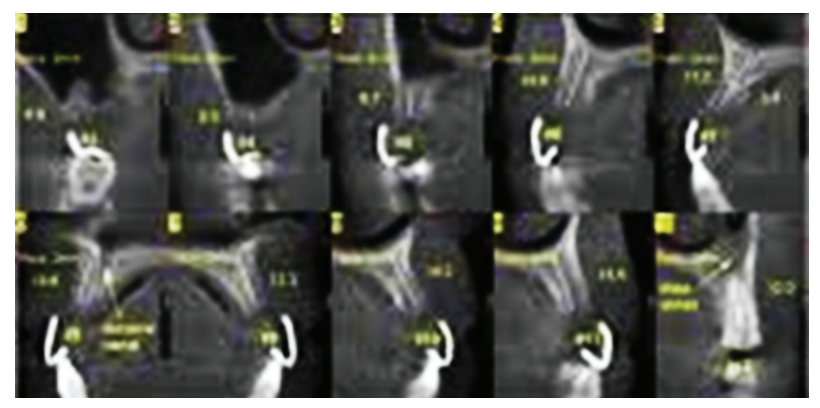

Figure 9: CBCT scan 


\section{Conclusion}

Proper planning is vital for successful implant treatment outcome. Prosthetically driven implant planning minimizes future prosthetic risks. Radiographic stent is the key for predictable implant placement. The present article explores a simplified technique for the fabrication of radiographic stent. This technique needs minimal skill and is very economical and requires decreased armamentarium and chairside time.

\section{References}

1. Engelman MJ, Sorensen JA, Moy P. Optimum placement of osseointegrated implants. 1988;59:467-68

2. Scherer MD. Presurgical implant-site assessment and restoratively driven digital planning. Dent Clin North Am 2014;58:561-95

3. Barbosa JM, Carames GB, Gill GG and Carames J. Adaptation of an interim partial removable dental prosthesis as a radiographic template for implant placement. J Prosthet Dent 2016;116:147-48

4. Almog DM, Torrado E, Meitner SW. Fabrication of imaging and surgical guides for dental implants. J Prosthet Dent 2001;85:505-7 